\title{
OPTIMIZING ENERGY CONSUMPTION IN BUILDING DESIGNS USING BUILDING INFORMATION MODEL (BIM)
}

\author{
Samuel EGWUNATUM ${ }^{1}$, Esther JOSEPH-AKWARA ${ }^{2}$, Richard AKAIGWE ${ }^{3 *}$
}

\section{Abstract}

Given the ability of a Building Information Model (BIM) to serve as a multi-disciplinary data repository, this paper seeks to explore and exploit the sustainability value of Building Information Modelling/models in delivering buildings that require less energy for their operation, emit less $\mathrm{CO}_{2}$ and at the same time provide a comfortable living environment for their occupants. This objective was achieved by a critical and extensive review of the literature covering: (1) building energy consumption, (2) building energy performance and analysis, and (3) building information modeling and energy assessment. The literature cited in this paper showed that linking an energy analysis tool with a BIM model helped project design teams to predict and create optimized energy consumption. To validate this finding, an in-depth analysis was carried out on a completed BIM integrated construction project using the Arboleda Project in the Dominican Republic. The findings showed that the BIM-based energy analysis helped the design team achieve the world's first $103 \%$ positive energy building. From the research findings, the paper concludes that linking an energy analysis tool with a BIM model helps to expedite the energy analysis process, provide more detailed and accurate results as well as deliver energy-efficient buildings. The study further recommends that the adoption of a level 2 BIM and the integration of BIM in energy optimization analyse should be made compulsory for all projects irrespective of the method of procurement (government-funded or otherwise) or its size.

\section{Address}

1 Department of Quantity Surveying, Delta State Polytechnic, Ozoro, Nigeria

2 Department of Civil Engineering, Delta State Polytechnic, Ozoro, Nigeria

3 Department of Building Plc, Institute of Builders, Lagos State, Nigeria

* Corresponding author: samuelegwunatum@gmail.com

\section{Key words}

- Building Information Modelling,

- Building energy performance analysis,

- Sustainability,

- Energy efficiency.

\section{INTRODUCTION}

The performance evaluation of a building can be divided into five parts: (1) the building envelope, (2) the air conditioning and ventilation, (3) the water heating system, (4) the dynamic equipment, and (5) illumination. However, the building envelope bas been recognized as the most important factor with regard to energy efficiency. If the properties of a building envelope can be improved upon, a good en- ergy-saving design can be achieved, which can lead to lower energy costs during operation as well as reduced energy waste and carbon dioxide emissions [1].

In order for a building to operate at its optimum capacity and functionality, a defined amount of energy has to be supplied. This requires estimating the amount of energy needed and equating the energy demand with the energy supply. In doing this, the demand side is calculated, cumulating energy losses such as transmission and ven- 
tilation heat losses of the building envelope [2]. Different methods of evaluating the energy performance of buildings have been identified and employed by different researchers.[3] applied a hybrid method in the energy analysis of building materials. They identified three types of energy analysis methods: (1) statistical analysis, (2) input-output analysis, and (3) process analysis. Whilst statistical analysis uses published statistics to evaluate energy usage, and input-output analysis equates energy usage with the monetary flow within the economy, process analysis deals with the systematic examination of the direct and indirect energy into a process. Similarly, and in a more detailed format, [2] classified energy performance analysis into two types: (1) physical calculation models and (2) statistical calculation models. They argued that a physical calculation model provides an exact calculation of detailed performance analysis tasks, while a statistical calculation model applies empirical factors in the performance analysis or a building, thereby making performance analysis estimates.

Whilst the above methods seem to have worked in the past, recent developments in computational simulations now make it possible to analyse a building envelope's performance efficiently.[4]reviewed current computational optimisation methods applied to sustainable building design problems. He identified three types of computational optimisation: (1) generic optimization, (2) multi-objective optimisation and (3) algorithms. [5] opined that "the quality of developed and used simulation model depends on the data available at the given stage of the project, the knowledge and experience of the modeler, available resources, and various other external conditions and pressure.

[6] provides the following factors to be considered when selecting a method/tool for evaluating a performance analysis: (1) the degree of accuracy, (2) its sensitivity, (3) Speed and cost of learning and using it, (4) its reproducibility, (5) its ease of use and level of detail, (6) the availability of the required data, (7) the quality of the output and (8) the stage of the project.

[1] and [2] provide key performance indices that are calculated to display the energy performance of buildings. These indices include: (1) average thermal transmittance, (2) ventilation heat losses, (3) solar heat gains, (4) internal heat gains, (5) lighting power, and (6) resulting heat demand. The USGSA (2008) provides possible results of energy analysis to include: (1) an assessment of the space and building energy performance for compliance with regulations and targets, (2) an overall estimate of the energy use by the space and for the building and an overall estimate of the energy costs, (3) a time-based simulation of the energy use of the building and a time based estimate of the utility costs, and (4) a lifecycle estimate of the energy use and cost of the building.

\subsection{Justification of the Study}

Global warming and its consequential climate changes are threatening the very existence of mankind. These changes have been attributed to anthropogenic activities and greatly affect a building's energy use, carbon footprint and its indoor climate. They may also contribute to sick buildings. [7] Provides an insight into the impacts of climate change on buildings. Their studies identified the following major impacts of climate change on buildings: (1) flooding, (2) the swelling and shrinking of soil that may affect foundations, (3) wind actions causing dynamic structural loading by pressure forces, and (4) driving rain leading to weathering. Similarly, [8] further identified: (5) an increased overheating and air-conditioning load, (6) increased greenhouse gas (GHG) emissions, and (7) increased costs due to carbon or GHG charges, as significant impacts of climate change on buildings.

Therefore, in order to reduce the negative effects of the aforementioned factors on buildings, there have been various levels of consensus amongst built environment professionals/regulatory bodies on the need to design and construct energy-efficient buildings. The conventional method of building energy analysis, however, provides few opportunities to wholly evaluate the relative energy performance of alternative designs as well as opportunities for information sharing [9]; [10].Similarly, [11] believes that since an energy analyst constructs an energy/thermal model from drawings, the probability of misinterpreting 2D/3DCAD information is high, which may lead to an inaccurate energy assessment. Whilst there has been much research in the area of building energy performance analysis, relatively little research has exploited and integrated a BIM model in their energy analysis process [9].[10];,[12]; [4]; [2]. Similarly, as to the limited amount of research in Building Information Modelling and energy performance analysis, there is little information available on the extent to which Building Information Modelling enhances the energy performance of buildings.

This research therefore seeks to establish the degree to which linking a BIM model with energy analysis software/tools will help deliver energy-efficient buildings. In addition, regarding the UK government's ambition to adopt level 2 BIM for all publicly-procured projectsfrom2016, this research also seeks to demonstrate the sustainability value of Building Information Modelling in delivering energy-efficient buildings.

\section{SURVEY OF THE LITERATURE ON BUILDING PERFORMANCE AND ENERGY ANALYSIS}

The current trends in world energy use have raised serious questions over the difficulties with supplies, the exhaustion of energy sources, and heavy environmental impacts [13]. According to the International Energy Agency, total world energy consumption increased by over $46 \%$ from 4,672 Mt to $8677 \mathrm{Mt}$ between 1971 and 2010(see Fig. 1); the amount of carbon dioxide emissions $\left(\mathrm{CO}_{2}\right)$ during this period increased by over $48 \%$ from $15,637 \mathrm{Mt}$ of $\mathrm{CO}_{2}$ to $30,326 \mathrm{Mt}$ of $\mathrm{CO}_{2}$ (Fig. 2). Due to the current climate changes and the consequential global warming, global demand for energy is soaring. The energy outlook shows that energy demands will continue to rise. According to [14], "global energy demand will increase by over onethird in the period of 2012 to 2035.Similarly, British Petroleum (BP) (2013) predicts that global primary energy consumption will grow by $1.6 \%$ per annum over the period of 2010 to 2030 , adding $36 \%$ to global consumption by 2030 . Whilst it is outside the scope of this research to validate the authenticity of these statistics, the predictions are nevertheless frightening. More worrisome is the fact that global carbon dioxide emissions are directly proportional to the amount of energy used. The world's population growth and economic development have been identified as factors contributing to global energy demands. [13] analysed the relationship between energy consumption, economic development, and population growth. They opined that urbanisation, globalisation, improvement of living conditions in emerging regions, and the development of communication networks, promote the lifestyle of developed nations' and increase energy needs to consumption patterns that, without doubt, will exhaust fossil fuels and produce serious environmental impacts [13].The situation has been confirmed for example, by China, where over 210 million rural inhabitants migrated to urban areas between 2002and 2012 (See Fig. 3).In the United States, the population of urban dwellers has been rising steadily from $79.4 \%$ in 2011 to over $82 \%$ in 2011 (See fig. 4). Similarly, the urban share of the population in the United Kingdom steadily increased by a small fraction from $78.72 \%$ in 2001 to $79.64 \%$ in 2011 (See Fig. 5). Meeting the needs of these urban dwellers therefore represents tremendous challenges and exerts much pressure on energy, as considerable resources are needed to invest in urban public utilities, infrastructure and services, including housing, the water supply, roads, and bridges [15]. 
Recent statistics released by the UK's Department of Energy and Climate Change show that the total UK primary energy consumption in primary energy terms (fuel obtained directly from a natural source) was 203 million tonnes of oil equivalent (See Fig. 6).The domestic sector accounted for about 20\% (38.8 million tonnes of oil equivalent) with the majority of the energy spent on space heating. Interestingly, this figure is the lowest level of UK primary energy consumption since 1984 [2].Improvements in the energy efficiency of electrical appliances as well as the energy efficiency of buildings have been identified as factors helping the UK to reduce total domestic energy consumption (See fig. 7) for support of this opinion.

World total final consumption from 1971 to 2010 by fuel (Mtoe)

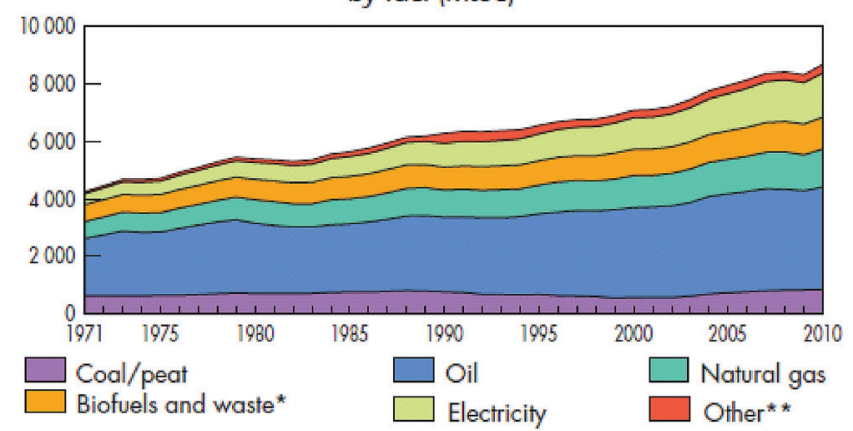

Source: IEA, 2013

Fig. 1 Total World Energy Consumption.

World* $\mathrm{CO}_{2}$ emissions** from 1971 to 2010 by fuel (Mt of $\left.\mathrm{CO}_{2}\right)$

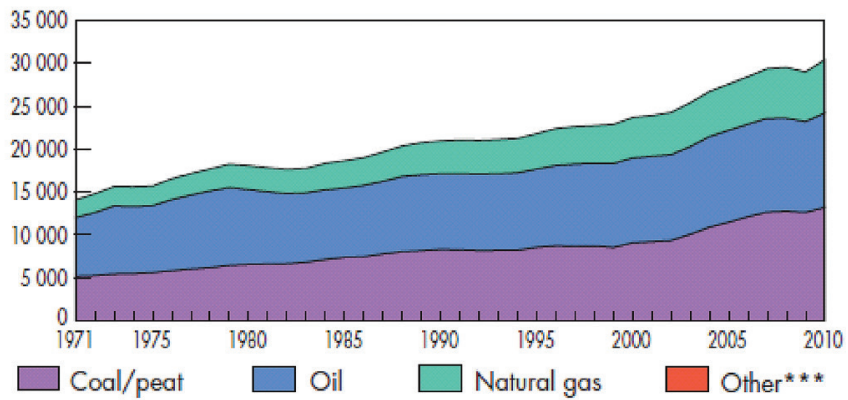

Source: IEA, 2013

Fig. 2 World Carbon Dioxide Emissions $\left(\mathrm{CO}_{2}\right)$.

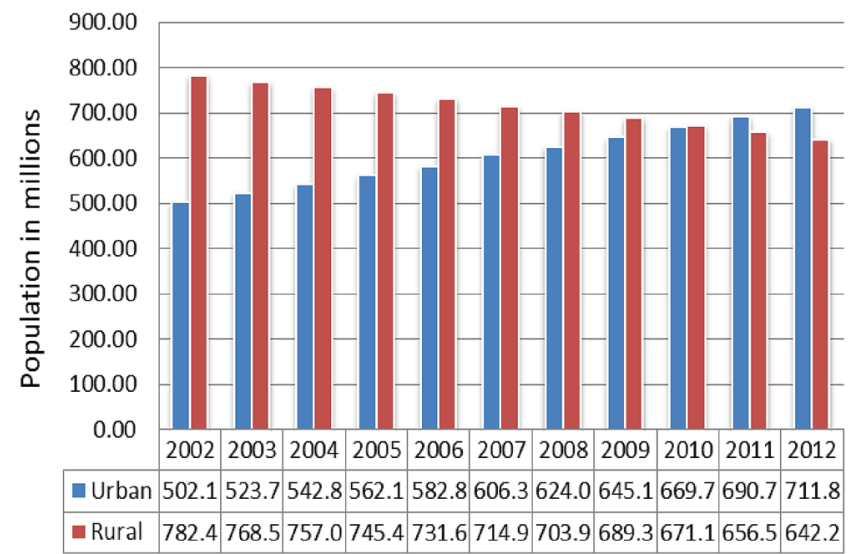

Source: Statista, 2013

Fig. 3 Degree of urbanisation in China from 2002 to 2012.

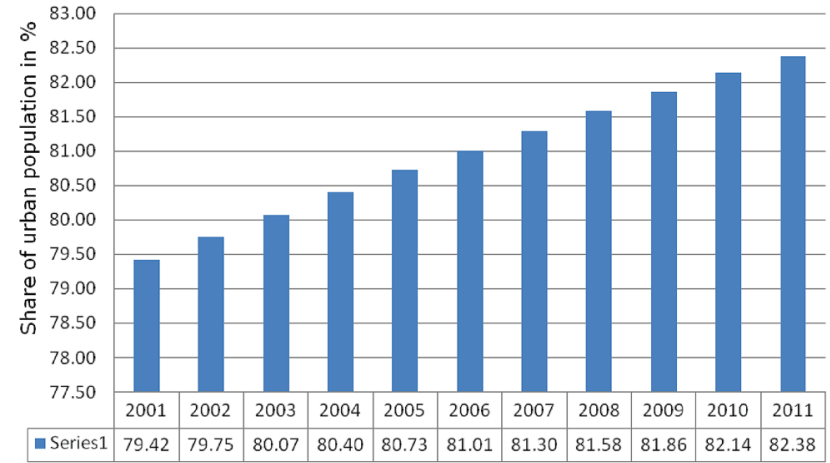

Source: Statista, 2013

Fig. 4 Degree of urbanization in the United States.

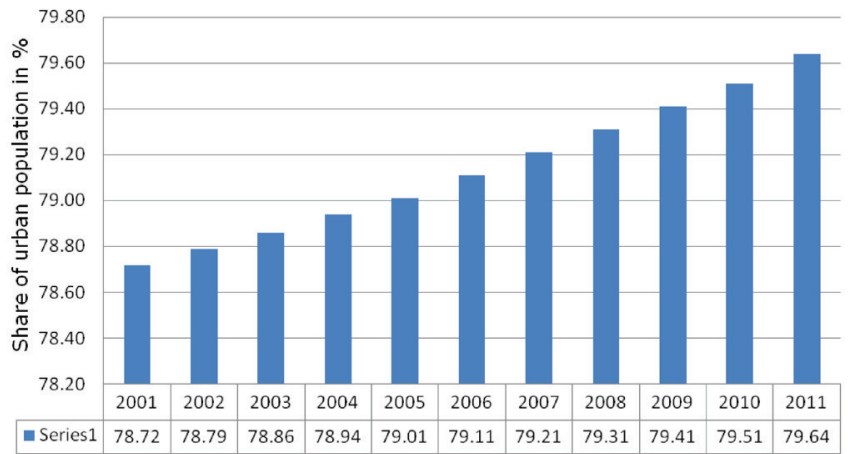

Source: Statista, 2013

Fig. 5 Degree of urbanization in the United Kingdom (2001-2011).

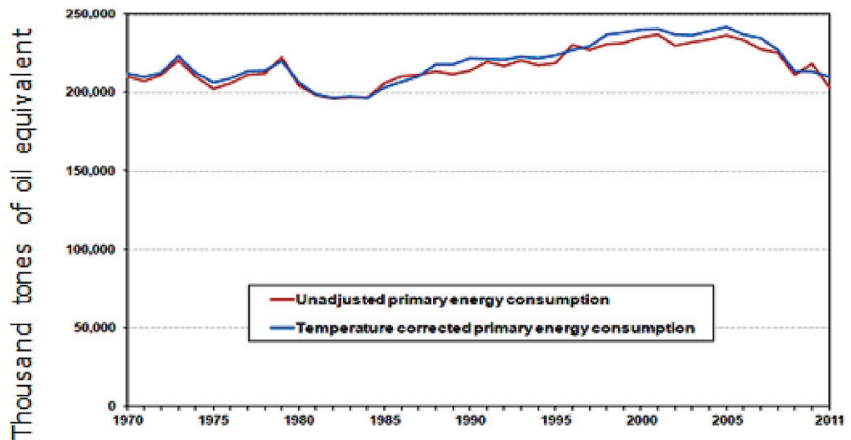

Source: DECC, 2013

Fig. 6 Total primary energy consumption, unadjusted and temperature corrected, UK, 1970 to 2011.

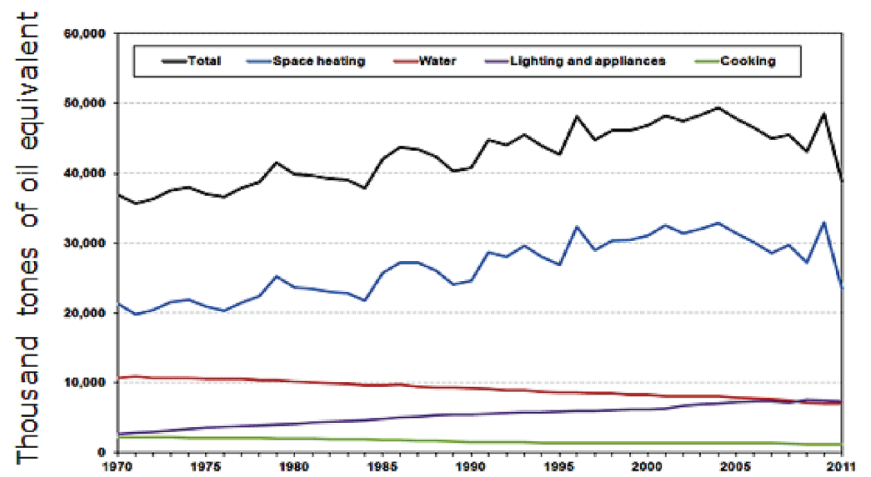

Source: DECC, 2013

Fig. 7 Net Domestic energy consumption by end use, UK 1970-2011. 
Tab. 1 Major Factors Affecting Building Energy Use.

\begin{tabular}{|c|c|c|}
\hline $\mathrm{S} / \mathrm{n}$ & Variables & Description \\
\hline 1 & Climate & $\begin{array}{l}\text { Heating degree-days } \\
\text { Cooling degree-days }\end{array}$ \\
\hline 2 & Building & $\begin{array}{l}\text { Floor area }\left(\mathrm{m}^{2}\right) \\
\text { Number of windows } \\
\text { Properties of the building envelope } \\
\text { Type of building } \\
\text { Year of construction }\end{array}$ \\
\hline 3 & Occupant & $\begin{array}{l}\text { Number of occupants } \\
\text { Total income }\end{array}$ \\
\hline 4 & Equipment & $\begin{array}{l}\text { Type of space heating equipment } \\
\text { Type of space cooling equipment Frequency }\end{array}$ \\
\hline 5 & $\begin{array}{l}\text { Occupants' } \\
\text { Behaviour }\end{array}$ & $\begin{array}{l}\text { Number of heated rooms } \\
\text { Average temperature setting Frequency } \\
\text { Number of cooled room }\end{array}$ \\
\hline
\end{tabular}

Adapted from Steemers and Yun,2009

\subsection{Building Energy Consumption}

The energy consumption of buildings primarily serves to make the indoor environment comfortable and habitable; these include space heating, cooling, domestic water heating, lighting, ventilation, and appliances. However, the energy uses of buildings are disproportionate are it's a function of many factors: time, type, size, weather and seasonal variations as well as occupants' behavioural patterns. Urbanization, as a factor has been covered in the preceding sections. [13]believes that "growth in population, enhancement of building services and comfort levels, together with the rise in time spent in side buildings, have raised building energy consumption". Similarly, [16], whilst studying the role of occupants in household energy consumption identified two major factors affecting the energy use of buildings i.e.,:

Direct factors and (2) indirect factors. Whilst direct factors include climatic and physical housing variables along with occupant choices and behaviour, indirect factors relate to a household's disposable income. Table 1 shows an overview of the major factors affecting building energy use. The energy use associated with buildings in the UK is enormous. A critical analysis of the trends in total domestic energy consumption between 1970 and 2011 (Figs. 6 and 7) shows that [2]:

a Domestic energy consumption in 2011 was over 38.9 million tonnes of oil equivalent, with $60 \%$ of that being used for space heating, while water heating, lighting and appliances accounted for 18,19 and $3 \%$, respectively;

b Domestic energy consumption in 2011 was $20 \%$ lower than in 2010. This is attributable to lower temperatures in 2010, which led to an increase in demand for space heating, as well as the promotion of energy-efficiency measures in homes.

\subsection{The Building Envelope}

As stated earlier, the building envelope mediates between the internal and external environments by forming a barrier to heat, light and air; therefore, it must be carefully designed to achieve a high degree of performance [4]. [4] has further demonstrated the optimization of a building envelope from three viewpoints: (1) construction, (2) form, and (3) double façade. Whilst the optimization of construction is focused on the selection of and variation in building materials based on their properties and form, optimization is concerned about varying building shapes and sizes. The double skin façades employ two layers of skin to improve the performance of the building envelope [4].

[10] identified the evaluation of the building envelope via the Overall Thermal Transfer Value (OTTV). The overall thermal transfer value (OTTV) is a measure of the heat gain into a building through the building envelope. The theory of the OTTV is based on the assumption that the envelope of a building is completely closed and consists of two values: (1) Envelope Thermal Transfer Value (ETTV) and Roof Thermal Transfer Value (RTTV) [17]. Whilst the ETTV is a measure of the heat transfer through the walls or envelope of a building, the RTTV is concerned with the heat transfer through the roof of the building.

[17] states the main objectives of the OTTV as include: (1) Developing and implementing of energy-efficient design protocols and relevant design tools, (2) establishing energy management benchmarks and developing a best practices system for various building types, (3) suggesting ways to improve energy efficiency in buildings, and (4) encouraging climate-responsive building planning and design. [18] identified four different methods of calculating the OTTV.They include: (1) the ASHRAE90A-80 method, (2) an equation derived by Chow and Chan, (3) the Hong Kong Code of Practice, and (4) using data generated a computer simulation by TRACE 600 .

\subsection{Building Energy Performance Analysis}

The term "building performance analysis" refers to the various assessments and evaluations conducted to determine a buildings environmental performance and includes such contextual analyses as: solar and thermal energy, ventilation, day lighting, building massing, site orientation as well as the optimization of a building's HVAC systems [19]. Building energy analysis seeks to predict the usage profile and cost of energy consumption within buildings in order to provide opportunities for improvements [20].These improvements come by ways of making energy-conscious decisions at the conceptual design stage which help the team detect and reverse energy-efficient defects in the construction process [9],[2]. [6] provides a rational for a building energy analysis. He opined that a building energy analysis is carried out to achieve the following:

- Evaluation of alternative designs, systems, subsystems, components;

- Allocation of annual energy budgets

- Compliance with energy standards

- Economic optimization

Buttressing this, Galloway et al. (2012), whilst carrying out a case study analysis of the energy performance of a building opined that "post occupancy evaluations of many different types of buildings have shown that there are large gaps between the design and actual performance". The European Union Building Energy Performance Directives provide a methodology for the calculation of the energy performances of buildings. This method shall include at a minimum, the following aspects:

- Thermal characteristics of the building (shell and internal partitions, etc.).These characteristics may also include air-tightness;

- Heating installation and hot water supply, including their insulation characteristics;

- Air-conditioning installation;

- Ventilation;

- Built-in lighting installation (mainly the non-residential sector);

- Position and orientation of buildings, including the outdoor climate;

- Passive solar systems and solar protection; 
- Natural ventilation;

- Indoor climatic conditions, including the designed indoor climate.

[9] identified the following factors influencing the energy performance of buildings: (1) climate, (2) design, and (3) occupants; Cong et al.(2010) expounded on the design factors as including: building sites, orientation, envelope configuration, and HVAC system functions. Buttressing this, [19], while arguing that the conceptual design phase of an energy analysis provides a design team with first order magnitude feedback about the impact of various building configurations on annual energy performance, opined that a building energy analysis must take account of the following as input data [19]:

- Building geometry, including the layout and configuration of spaces;

- Building orientation;

- Building construction, including the thermal properties of all construction elements, including walls, floors, roofs/ceilings, windows, doors, and shading devices;

- Building usage, including functional use;

- Internal loads and schedules for lighting occupants, and equipment,

- Heating, ventilating, and air-conditioning (HVAC) system type and operating characteristics;

- Space conditioning requirements;

- Utility rates;

- Weather data.

\subsection{Building Information Modelling and Energy Performance Analysis}

Building performance analysis is typically performed after the architectural design and construction documents have been produced [19].In the traditional process, the building geometric information is extracted from the architectural drawings which depict the architect's view of the building. Thereafter, the building energy analyst uses this information to define the thermal view of the building. This definition is subjective and is dependent on the knowledge, skill and experience of the energy analyst. Various building energy analysts will therefore generate differing thermal views [5].

According to [19], the most effective decisions related to the sustainable design of a building can only be made in the design and preconstruction stages. The literature notes that due to the lack of a continuous analysis of a building's performance, the traditional approach leads to an inefficient process of retroactively modifying a design to achieve an agreed set of performance criteria [2].[21] identified this as the problem of a "solitary information island". They further opined that the detachment of energy-saving technology from a building design, as evidenced in the traditional approach, present real problems for energy performance analyses.

A Recent advance in construction informatics now addresses the complex problem of integrating building energy performance analysis and building design. In order to do this, access to a complete set of information that defines a building such as form, materialization and technical systems is necessary [2].One rapidly evolving technology that has been envisioned and demonstrated to support building energy performance analysis is the Building Information Modeling (BIM) [22], [2]; [10]. Building Information Modeling has the ability to serve as an independent, multi-disciplinary data repository, which provides new opportunities and approaches for integrating performance analysis into possible designs [2].

[23] Proposed the development of an Energy BIM. They believe that since the early stages of the design process are characterized by limited information, which may affect an energy performance analysis, a simple Energy BIM can be developed which will enable a 'sketch' to be made of the building's energy performance.[23]further expounded on the Energy BIM as a combination of data from a building information model (BIM) with additional information such as building use, HVAC system details, building spaces and the occupancy level, which can be used to produce repositories of simulated building and system performances, the complexities of which will, by necessity, vary according to the building's lifecycle [23].

The contribution of BIM to sustainable design and performance analysis is demonstrated from the perspective of integrated project delivery and design optimization [24] [25].[25] further sees the visualization and day lighting capabilities of BIM as contributing to sustainable design and energy performance evaluations.[25] provides a summary of the potential of BIM in sustainable design and energy analysis. It includes:

- Building orientation(to select the best building orientation that results in minimum energy costs)

- Building massing (to analyse a building's form and optimize the building envelope)

- Daylighting analysis

- Water harvesting(to reduce the water needs of a building)

- Energy modelling (to reduce energy needs and analyse renewable energy options such as solar energy)

- Sustainable materials(to reduce material needs and use recycled materials)

Buttressing Krygiel and Nies' submission, [22] highlighted the application of BIM in the design processes from four viewpoints: (1) conceptual design, (2) design and analysis, (3) the development of construction-level information, and (4) design and construction integration. In the conceptual design phase, they believe that BIM will have a huge impact on strengthening the decisions made relating to a building plan, its massing, appearance, placement and orientation. With respect to other aspects of building performance analysis, [22] claimed that the application of BIM has beneficial inputs in the functional aspects of building performance such as structural integrity, temperature control, ventilation, lighting, circulation, acoustics, energy distribution and consumption, and water supply and disposal. They further argued that success here "demands intense collaboration among a team of specialists, requiring a mix of configurable tools that, when combined, form a design workbench [22].

\subsection{Benefits of BIM Integrated Energy Performance Analysis}

[19] analysed the current state and benefits of BIM-based sustainability by administering a questionnaire to professionals within the subject area. Their findings revealed that:

- Practitioners use BIM for: (i) energy analysis, (ii) day lighting/ solar analysis, (iii) building orientation analysis, (iv) massing analysis and (v) site analysis

- Practitioners using BIM-based sustainability analyses realised some significant time savings

- Practitioners using BIM-based sustainability analyses realized significant cost savings

- The prevalent software used was: (i) AUTODESK Ecotect ,(ii) Autodesk Green Building Studio (GBS ${ }^{\mathrm{TM}}$, and (iii) Integrated Environmental Solutions (IES) Virtual Environment ${ }^{\mathrm{TM}}$. 


\section{METHODOLOGY}

A case study approach was exploited in order to provide an indepth analysis of BIM-based energy analysis and the energy performance of buildings. This approach is supported by [26]who stated that "case studies are used when a researcher intends to support his/ her argument by an in-depth analysis of a person, group of persons, a group, an organization or a particular project".

[26] further provided three types of case study designs: (1) descriptive, (2) analytic, and (3) exploratory. Whist a descriptive case study focuses on answering such questions posed as : how, what, who, where and when; the analytic case study is concerned with the association and relationship between attributes. In addition, an exploratory case study explains and tries to show the connection amongst the objects of research [26].This research employs the three types of case study because the investigation anticipates that the research findings will reinforce the relationship and connection between BIM-based energy analysis and the energy performance of buildings.

For the purpose of this investigation, theArboleda Open BIM Project in the Dominican Republic was chosen because building information modeling (BIM) was used in the design/construction. In addition, building information modeling was used in the sustainability and energy analysis of the project.This choice is in line with the argument of [27] who posited that a case study may be selected on the basis of being representative to those used in statistical sampling to demonstrate the particular facets of a topic.

\subsection{The Case Study Approach}

According to [27], case study employs interviews of key 'actors' in the subject of the study. [27] further provided that such interview data may be coupled with the scrutiny of any documentation. With the above in mind, the following processes were used in the analysis of the above case study project:

- Identification of suitable case study projects

- Review of the project's method of design and construction (from the literature)

- Interview with the project professional responsible for the building energy analysis (where necessary)

- Discussion of the benefits and/or constraints of linking an energy analysis software with a BIM model

- Presentation of findings

\subsection{Case Study Reports}

\subsubsection{The Arboleda Open BIM Project}

Source: The material for the above case study was sourced from the following online articles and videos:

Nemetschek Vector works: Arboleda Open BIM Project

The Arboleda Open BIM project is a multi-family, multistorey, urban in-fill residential development in Santa Domingo, the Dominican Republic. The project was executed in a small BIM approach utilizing works Vector Architect software and completed in 2011. However, the use of works Vector Architect software was limited to architectural purposes only. After completing the project, Nemetschek works Vector, together with its global partners, decided to conduct an in-depth investigation of the project and recorded what could have happened if the project had been delivered using a collaborative Open BIM approach based on the IFC file format. (See fig. 8 for the comparative conceptual framework of the project without linkage to BIM software)

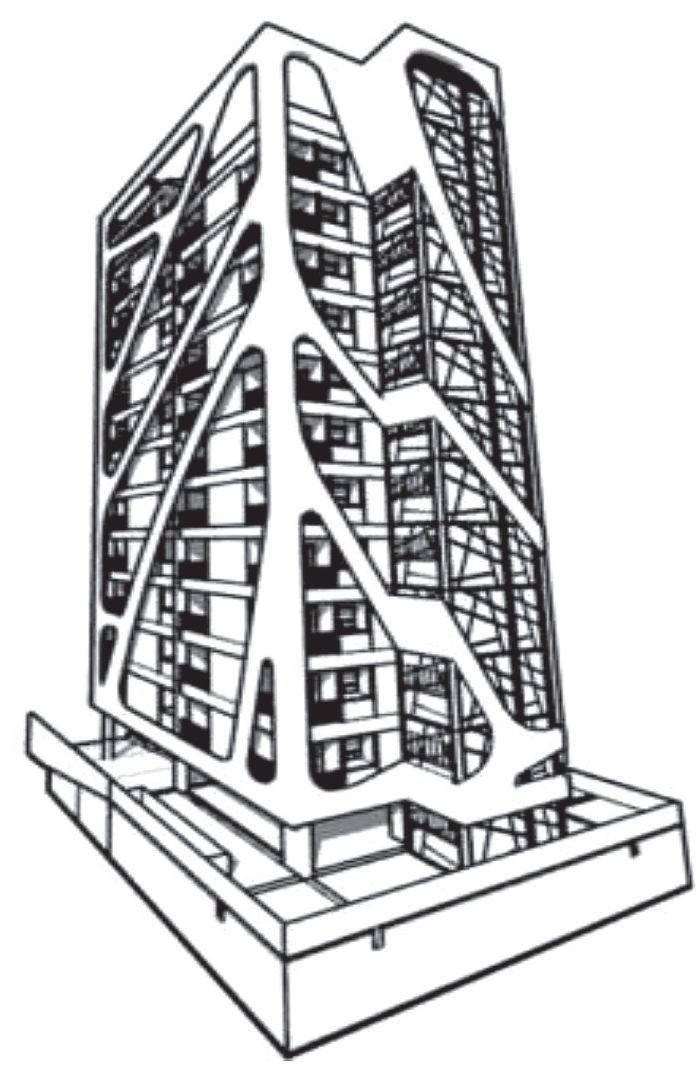

Fig. 8 Initial Project Concept.

\subsubsection{Initial Concept}

The design process began with a concept sketch. The sketch was made to be legible enough to communicate a partial relationship. Once the sketch was finished, it was imported directly into works Vector Architect software as an image file. Thereafter, this image file was traced over, extruded to the correct height, and refined by using the push/pull tool to produce a massing model. The works Vector Architect sotfware was used because it excels as a tool for BIM design and BIM authoring whilst opening opportunities for interoperability and collaboration between team members and project collaborators. This interoperability was only possible due to the use of IFC and in accordance to the open BIM Program, the team members were allowed to work with their best in class software.

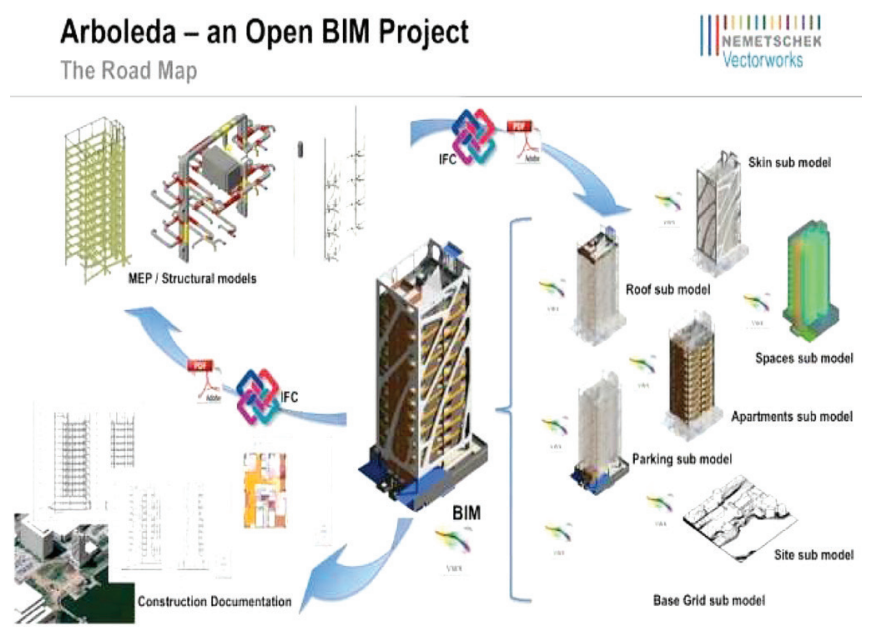

Fig. 9 Arboledaproject BIM Road Map. 


\subsubsection{Integrating Energy Analysis with the BIM Mode}

Integrated Environmental Solution VE software was used for the energy analysis and simulation for the Arboleda project. The SOLIBRI model checker was used to query the component information and areas of the BIM model. It also validated the modelling spaces to allow for a successful import with IES VE through the IFC format.

Linking the IESVE software to the BIM model allowed the team to carry out an accurate solar analysis and visualization of the project at different times and days of the year. In order to understand the solar behaviour of the building, the team introduced a solar path on the BIM model (See fig. 9).This helped in determining the requisite solar shading needed for the project.

In addition, the team were able to carry out: (1) an analysis of heating and cooling loads for the building as a whole, as well as providing them with an idea of the climatic and weather conditions around the project, (2) an analysis of the wind loads based upon the height and orientation of the building, (3) a graphic representation of the day time -night-time temperatures on a monthly average, (4) an in-depth analysis and rendering of luminosity within the building spaces, and (5) an assessment of the energy usage and lifecycle costing of the BIM model as exemplified in fig. 10.

\subsubsection{Justification}

The Building Information Modelling used on the project is an efficient way to design. It maximizes resources and thus the ability to make profit. It increases coordination between the consultants meaningless risk/unknowns when the building is on site.

BIM was used from Stage D (when the designs were developed and fixed).It was used to provide all the architectural and structural drawings. However, we noted that the contract was always 2D paper draw- ings, which were generated from theBIM model. The M+E sub-contractor also used the BIM model for their information/spatial fit.

All together, the project was designed using BIM. It was also incorporated in a passive design initiative by careful selection of the building materials, including exposed concrete for the thermal mass, thermal insulation and a façade designed to maximize the daylight but control the solar gain. These features were set prior to the implementation of BIM, and the $\mathrm{M}+\mathrm{E}$ consultant used their own modeling systems for the thermal modeling and sustainability analysis carried out in Stages A-C. It was implemented at this stage in order to show the design development and outline the costs.

\section{CASE STUDY DISCUSSIONS}

The above case studies have demonstrated some of the sustainability benefits of linking energy analysis software to a BIM model. This integration has proven to produce a fast and accurate analysis of the model data during the conceptualization and design phases of projects. The Design team members are able to create and simulate several design scenarios, visualize their implications as well as make very informed decisions.

For the Arboleda project, the design team exploited the numerous benefits of Building Information Modelling to analyse and optimize the properties of the building form for reduced energy consumption. For example, the close integration of the BIM model with the energy analysis tools enhanced the design team's ability to evaluate its design assumption as well as making well informed decisions. In addition, the design team were able to capitalized on the take-offs generated from the BIM model in order to quantify the consumption of the natural resources and aid in forecasting the use of sustainable materials

With the BIM and energy analysis integration, the project team was also able to: (1) prepare a more accurate cost and budget model,

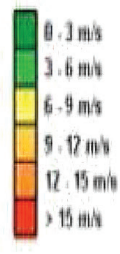

\section{$=$}

12 int

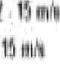

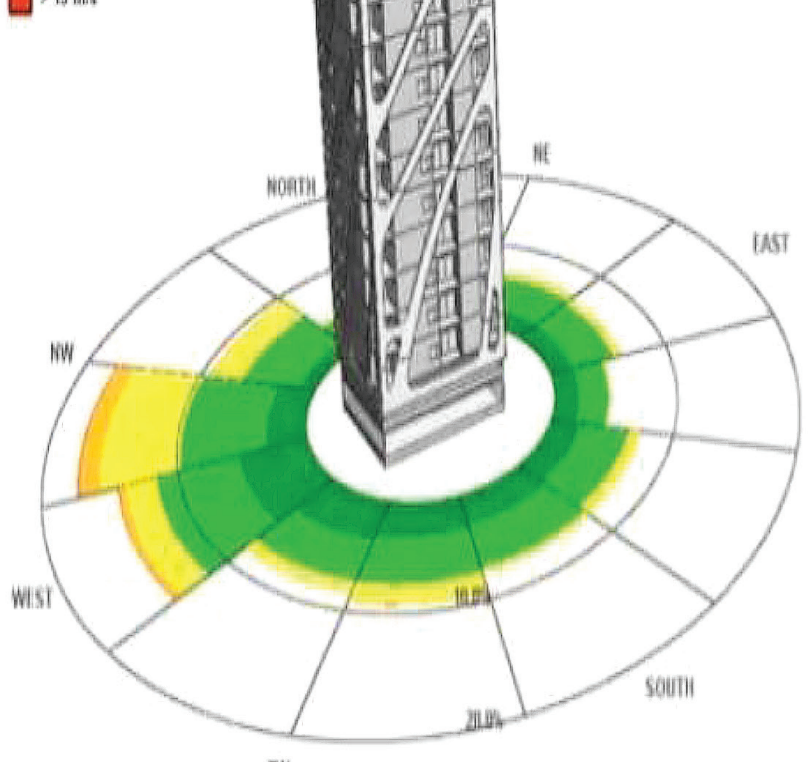

WW

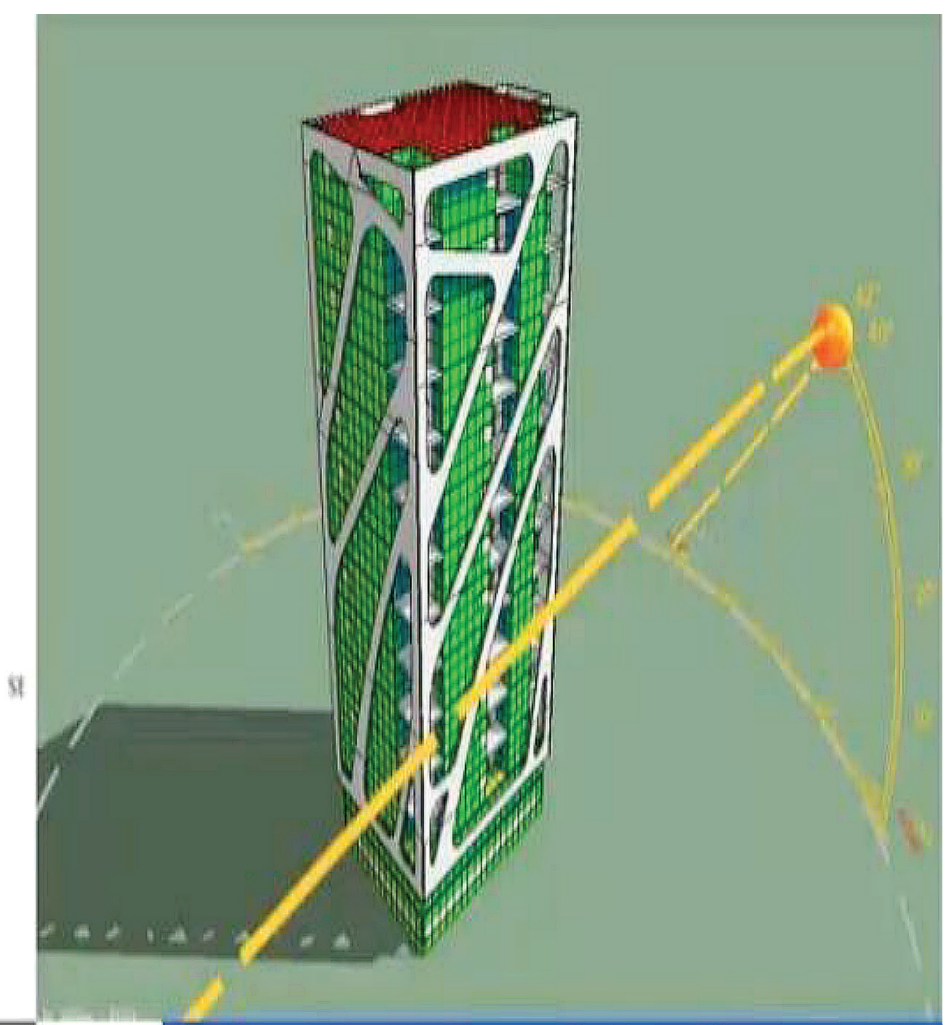

Fig. 10 Arboleda BIM-based energy analysis showing the windrose and solar path on the BIM model.

Source: the material for the above case study was sourced from the following online articles and videos:

Nemetschek Vector works: Arboleda Open BIM Project 
(2) keep track of items such as the total recycled content and embodied carbon dioxide level, (3) set carbon targets for specific project elements, (4) compare design options as well as validate design decisions, (5) see real-time updates on the project's carbon content, and (6) generate fewer RFIs during construction. The result of the BIM and energy analysis integration was the delivery of the world's first positive energy building.

In addition, the case study on the Arboleda project confirmed that: (1) the use of building information modeling is an efficient way to design and construct buildings, (2) the use of building information modeling increases project coordination and reduces risks, and (3) the use of BIM maximizes project resources and increases productivity and profitability.

\section{CONCLUSION}

This research was undertaken to establish the sustainability value of Building Information Modelling linking a BIM model to an energy analysis software/tool not only to expedite the energy analysis process, but also to helps in delivering more detailed and accurate results. In the case study, we were also able to demonstrate via real project that Building Information Modelling facilitates the evaluation of different sustainability strategies.
The application of Building Information Modelling to building energy performance assessment contributes/enhances the energy performance of a building during its operation; linking a BIM model to energy analysis software enhances the energy performance of a building. The case study demonstrated that integrating BIM in the sustainability/energy analysis process helped the team to deliver a building that is $103 \%$ positive energy (103\% more efficient). Whilst there are many established benefits of using Building Information Modelling in design and construction, the findings from this research show that its adoption by stakeholders for sustainability/energy analysis is still low.

\section{Recommendations}

The following recommendations are hereby made:

- That BIM-based sustainability/energy analysis should be made mandatory for all projects irrespective of their size. By so doing, more energy efficient buildings can be produced.

- That research and development into cost-effective BIM-based energy analysis software/tools be carried out. By so doing, more stakeholders and industry personnel will have the wherewithal to adopt Building Information Modelling not just for design and construction, but also for integrating BIM in the energy performance analysis of buildings. 


\section{REFERENCES}

[1] Hsieh, C., and Wu, I., 2012. Applying Building Information Modelling in Evaluating Building Energy Performance. Geron technology Journal. [Online]. 11(2), pp. 170. Available from:http://dx.doi.org/10.4017/gt.2012.11.02.227.00 [Accessed 17 May 2013].

[2] Schlueter, A., and Thesseling,F., 2009. Building Information Model Based Energy/Energy Performance Assessment In Early Design Stages. Journal of Automation in Construction. [Online].18(2),pp. 153-163. Available from:http://www.sciencedirect.com/science/article/pii/S0926580508001064 [Accessed 20 April 2013].

[3] Alcorn, J. A. and Baird, G., 1996. Use of a hybrid energy analysis method for evaluating the embodied energy of building materials. Renewable Energy. [Online]. 8(1-4), pp. 319-322. Available from: http://www.sciencedirect.com/science/article/ pii/0960148196888690 [Accessed 28 May 2013].

[4] Evins, R., 2013. A review of computational optimisation methods applied to sustainable building design. Renewable and Sustainable Energy Reviews. [Online]. 22(1), pp. 230-245. Available from: http://www.sciencedirect.com/science/article/pii/ S1364032113000920 [Accessed 23 May 2013].

[5] Bazjanac, V., 2007. Impact of the U.S. National building information model standard (NBIMS) on building energy performance simulation. In Proceedings of the $10^{\text {th }}$ International Building Performance Simulation Association Conference. 0306 September 2007. Beijing, China. pp. 1337-1382. Available from: http://www.ibpsa.org/proceedings/BS2007/p749 final. pdf [Accessed 24 May, 2013]

[6] Al-Homoud, M. S., 2001. Computer-aidedbuildingenergy analysis techniques.JournalofBuildingand Environment. [Online]. 36(4), pp. 421-43. Available from: http://www.sciencedirect. com/science/article/pii/S0360132300000263 [Accessed 28 May 2013].

[7] Sanders, C. H. and Phillipson, M. C., 2003. UKadaptation strategy and technical measures: the impact so climate change on buildings. Building Research and Information. [Online]. 31(3-4), pp. 210-221. Available from: http://dx.doi. org/10.1080/0961321032000097638 [Accessed 20 May 2013]

[8] Camilleri, M. Jaques ,R. and Isaacs, N., 2001. Impacts of climate change on building performance in New Zealand. Building Research andInformation. [Online]. 29(6), pp. 440-450. Available from: http://dx.doi.org/10.1080/09613210110083636 [Accessed 20 May 2013].

[9] Michelle, 2009. BIM-based Building Performance Modelings. Traditional Building Performance Modeling.[online].Glasgow: Integrated Environmental Solutions [Accessed 24 May 2013].

[10] Capper, G., Matthews, J., and Lockley, S., 2012. Incorporatingembodiedenergyin the BIM process. In: CIBSE ASHRAE Technical Symposium. 18-19 April 2012. London, UK: Imperial College Availablefrom: http://nrl.northumbria.ac.uk/5859/

[11] Perez-Lombard, L., Ortiz, J., and Pout, C., 2008. A review on building energy consumption information. Journal of Energy and Buildings. [Online]. 40(3), pp. 394-398. Availablefrom:http://www.sciencedirect.com/science/article/pii/ S0378778807001016 [Accessed 25 May 2013].
[12] IEA, 2012. World Energy Outlook 2012.The International Energy Agency. OECD Publishing

[13] Li, B. and Yao, R., 2009. Urbanisation and its impact on building energy consumption and efficiency in China. Renewable Energy journal. [Online]. 34(9), pp. 1994-1998. Available from: http://dx.doi.org/10.1016/j.renene.2009.02.015 [Accessed 25 May 2013].

[14] Steemers, K. and Yun, G. Y., 2009. House hold energy consumption: a study of the role of occupants. Building Research and Information. [Online]. 37(5-6), pp. 625-637. Available from:http://dx.doi.org/10.1080/09613210903186661 [Accessed 25 May 2013].

[15] Evins, R., 2013. A review of computational optimization methods applied to sustainable building design. Renewable and Sustainable Energy Reviews. [Online]. 22(1), pp. 230-245. Available from: http://www.sciencedirect.com/science/article/pii/ S1364032113000920[Accessed 23May 2013].

[16] Vijayalaxmi, J., 2010. Concept of Overall Thermal Transfer Value (OTTV) in Design of Building Envelope to AchieveEnergyEfficiency. International Journal of Thermal \& Environmental Engineering. [Online]. 1(2), pp.75-80. Available from: http://www.iasks.org/sites/default/files/ijtee20100102075080. pdf [Accessed 1 June 2013].

[17] Chow, W. K., \& Yu, P. C., 2000. Controlling building energy use by overall thermal transfer value (OTTV). Journal .[Online] .25(5),pp. 463-478.Availablefrom: http://dx.doi. org/10.1016/S0360-5442(99)00079-1[Accessed19May2013]. Cohen,L.,Manion,L.,andMorrison, K., 2011.Research methods ineducation. $7^{\text {th }}$ ed.NewYork:Routledgepublishers.

[18] Azhar, S. and Brown, J., 2009. BIM for sustainability analyses. International Journal of Construction Education and Research. [Online].5(4), pp. 276-292. Availablefrom: http://www.tandfonline.com/doi/pdf/10.1080/15578770903355657 [Accessed 28 May 2013].

[19] U.S. General Service Administration, 2009. Information Delivery Manual for BIM Based Energy Analysis as Part of the Concept Design BIM 2010. [Online]. Washington, United States: General Service Administration [Accessed 28 May 2013].

[20] Yuan,Y.,andYuan,J., 2011. The theory and frame work of integration design of building consumption efficiency based onBIM.ProcediaEngineering. [Online].15(1),pp.5323-5327. Availablefrom:http://www.sciencedirect.com/science/article/ pii/S187770581102488X [Accessed 13 May 2013].

[21] Eastman, C. etal., 2008. BIM Handbook: A Guide to Building Information Modeling for Owners, Managers, Designers, Engineers , and Contractors. New Jersey, Hoboken: John Wiley and Sons

[22] Crosbie,T.,Dawood, N., and Dawood,S., 2011. Improving the energy performance of the built environment: Thepotentialofvirtualcollaborativelifecycletools.AutomationinConstruction. [Online].20(2),pp.205-216.Availablefrom: http://www.sciencedirect.com/science/article/pii/S0926580510001470 [Accessed 20 May 2013]. 
[23] Wong, K. D.,and FAN, Q.,2013. Building information modeling (BIM) for sustainable building design. Facilities Journal. [Online]. 31(3/4), pp. 138-157. Available from: http://dx.doi. org/10.1108/02632771311299412 [Accessed 25 May 2013]

[24] AUTODESK, 2004. Building Information Modeling for Sustainable Design. [Online]. United States: AUTODESK Revit White Paper. Available from:http://images.autodesk.com/adsk/ files/bim_for_sustainable_design_oct08.pdf [Accessed 17 May 2013].

[25] Krygiel, E., and Nies, B., 2008.GreenBIM: Successful Sustainable Design with Building Information Modeling. Indianapolis: Wiley Publishing
[26] Naoum, S. G., 2007.Dissertation research and writing for construction students. $2^{\text {nd }}$ ed. Oxford: Elsevier Publishing Ltd.

[27] Fellows, R. and Liu, A.,2008. Research methods for construction. $3^{\text {rd }}$ ed. Chichester: Wiley-Blackwell Publishing Ltd.

[28] Galloway, J. N., John, D. A., Eriamn, J. W., Seitzinger, S. P., Howarth, S. P., Cowling, E.B., Cosb, B. J., 2003. The Nitrogen Cascade. Bio. Science 53 (4), 534-356. 